\title{
Optic nerve sheath diameter on computed tomography not predictive of neurological status post-cardiac arrest
}

\author{
Barret Rush, MD**; Andrew Wormsbecker, MD*; Landon Berger, $\mathrm{MD}^{*}{ }^{\dagger}$; Katie Wiskar, $\mathrm{MD}^{*}$; \\ Mypinder S. Sekhon, MD*; Donald E. Griesdale, MD, $\mathrm{MPH}^{* \dagger}$
}

\begin{abstract}
Objective: Optic nerve sheath diameter (ONSD) measured on a head computed tomography (CT) has been suggested as a potential prognostic factor for poor neurological outcome after cardiac arrest. We performed a single centre retrospective cohort analysis to further investigate this relationship.

Methods: All patients $>18$ years of age admitted to St. Paul's Hospital in Vancouver, Canada who survived a cardiac arrest and had a CT scan of the head within 48 hours were included in the analysis.

Results: A total of 72 patients met inclusion criteria for the study; $54(75.0 \%)$ of the patients had a poor neurological outcome, whereas 18 (25.0\%) patients were discharged from the hospital with a good outcome. A CT head was obtained for patients in the good outcome group in a mean time of 9.3 hours (SD 10.0) compared to 10.2 hours (SD 11.2) for the poor outcome group $(p=0.75)$. There was no difference in average ONSD observed between the two outcome groups (6.66 mm SD 0.78 v. $6.60 \mathrm{~mm}$ SD 0.82, $p=0.77$ ). Multiple logistic regression failed to show any association between ONSD and neurological outcome when adjusted for all other covariates (OR $1.3295 \% \mathrm{Cl} 0.40-4.34, p=0.65$ ). Setting an ONSD threshold of $>8 \mathrm{~mm}$ (OR 2.32, 95\% Cl 0.14-39.40, $p=0.55$ ) or $>7 \mathrm{~mm}$ (OR $0.28,95 \% \mathrm{Cl} 0.03-2.77, p=0.28$ ) also failed to show any association on neurological outcome. Conclusion: There was no observed difference in ONSD between those with a good neurological outcome and those with a poor outcome. ONSD was not an independent predictor of poor neurological outcome.
\end{abstract}

\section{RÉSUMÉ}

Objectifs : Certains sont $d^{\prime}$ avis que la mesure du diamètre de la gaine du nerf optique par une tomodensitométrie (TDM) de la tête pourrait se révéler un facteur pronostique possible de séquelles neurologiques graves à la suite d'un arrêt cardiaque. Les auteurs de l'étude ont donc procédé à une analyse rétrospective, unicentrique de cohorte afin d'approfondir l'existence de la relation.

Méthode: Tous les patients âgés de plus de 18 ans, admis à I'hôpital St-Paul à Vancouver, au Canada, qui ont survécu à un arrêt cardiaque et qui ont subi une TDM de la tête dans les 48 heures ont été inclus dans l'analyse.

Résultats: Soixante-douze patients respectaient les critères d'inclusion dans l'étude; sur ce nombre, 54 (75,0 \%) ont connu des séquelles neurologiques graves, tandis que $18(25,0 \%)$ sont sortis de I'hôpital dans un bon état. II s'est écoulé en moyenne 9,3 heures (écart-type $[\sigma]: 10,0$ ) avant que la TDM de la tête soit réalisée dans le groupe ayant connu une évolution favorable contre 10,2 heures $(\sigma: 11,2)$ dans le groupe ayant connu une évolution défavorable $(p=0,75)$. Aucun écart n'a été relevé entre les deux groupes en ce qui concerne le diamètre moyen de la gaine du NO $(6,66 \mathrm{~mm}$; $\sigma: 0,78$ contre $6,60 \mathrm{~mm} ; \sigma: 0,82 ; p=0,77)$. Plusieurs analyses de régression logistique ont été réalisées, et aucune n'a démontré l'existence d'une relation entre le diamètre de la gaine du NO et l'état neurologique après rajustement de toutes les autres covariables (risque relatif approché [RRA] : 1,32; IC à $95 \%: 0,40-4,34 ; p=0,65)$. Il en est allé de même après l'établissement $d$ 'un seuil de diamètre de la gaine du NO > $8 \mathrm{~mm}$ (RRA : 2,32; IC à 95\%:0,14-39,40; $p=0,55$ ), puis $>7 \mathrm{~mm}$ (RRA : 0,28 ; IC à $95 \%: 0,03-2,77$; $p=0,28)$.

Conclusions: Aucune différence relative au diamètre de la gaine du NO n'a été observée entre les patients qui ont connu une évolution neurologique favorable et ceux qui ont connu une évolution neurologique défavorable. Le diamètre de la gaine du NO n'est donc pas un facteur prévisionnel indépendant de séquelles neurologiques graves.

Keywords: cardiac arrest, optic nerve sheath diameter, prognosis

From the *Division of Critical Care, Department of Medicine and; tDepartment of Anesthesia, Pharmacology and Therapeutics, Vancouver General Hospital, University of British Columbia, Vancouver, BC; ¥Harvard T.H. Chan School of Public Health, Harvard University, Boston, MA; and §Centre for Clinical Epidemiology and Evaluation, Vancouver Coastal Health Research Institute, Vancouver, BC.

Correspondence to: Barret Rush, Vancouver General Hospital, University of British Columbia, Room 2438, Jim Pattison Pavilion, 2nd Floor, 855 West 12th Avenue, Vancouver, BC V5Z 1M9; Email: bar890@mail.harvard.edu. 


\section{INTRODUCTION}

Hypoxic-ischemic brain injury (HIBI) after cardiac arrest often leads to death or incapacitation; however, some patients may have a favorable neurological outcome, justifying aggressive interventions. Avoiding such interventions in unsalvageable patients is economically and morally advised; however, accurate prognosis of HIBI remains a challenge. The role of imaging in the prognosis of HIBI has been limited by an absence of well-designed studies, and no specific guidelines regarding the use of imaging to guide the treatment of HIBI exist. ${ }^{1}$

A common technique to image the brain after cardiac arrest is computed tomography (CT), which is often performed to exclude a neurological etiology. CT may reveal secondary injury and edema after cardiac arrest, suggesting a poor clinical course. However, these findings usually appear on the second day or later, and cerebral edema is only present in approximately 30 percent of patients. ${ }^{2,3}$ Indeed, patients may recover meaningful neurological function, despite evidence of extensive injury on imaging. ${ }^{4}$ Furthermore, findings on imaging may create a self-fulfilling prophecy. Clinicians may recognize abnormalities on imaging and restrict treatments, fostering a link between those findings and poor clinical outcome. ${ }^{5,6}$

One prognostic factor on imaging that has received recent attention is the optic nerve sheath diameter (ONSD). The optic nerve sheath is an extension of the dura and contains cerebrospinal fluid (CSF) and the optic nerve. CSF shunts into the optic nerve sheath in the setting of brain injury and edema, causing the ONSD to increase. ${ }^{7,8}$ Cerebral edema increases the intracranial pressure (ICP). ONSD has been shown to correlate with ICP and with outcome in the setting of traumatic brain injury (TBI). ${ }^{9,10}$ In TBI, ICP monitoring as a means to guide therapy is the standard of care, and the ONSD may be a useful surrogate. ${ }^{11}$

Whereas the role of ICP monitoring in TBI is well established, its role in HIBI is less clear. Kim et al. recently reported that, in patients with HIBI in the emergency department, the ONSD as measured by CT closely correlated with neurological outcome. ${ }^{12}$ The purpose of our study was to further investigate the relationship between ONSD and functional outcome in patients who have HIBI after cardiac arrest.

\section{METHODS}

This was a single-centre retrospective cohort study and is reported as per the strengthening the reporting of observational studies in epidemiology (STROBE) guidelines. ${ }^{13}$ The University of British Columbia Research Ethics Board approved the protocol and waived consent (H14-01664).

\section{Population and study setting}

We used a database of all patients admitted to the coronary care and intensive care units at St. Paul's Hospital between 2009 and 2013 to identify patients with a head CT performed within 48 hours after surviving cardiac arrest. Both out-of-hospital and in-hospital arrests were included in the analysis. Exclusion criteria included age less than 18 years, death within 6 hours of admission, and patients transferred from another institution. A flow diagram detailing cohort selection is displayed in Figure 1.

\section{Data acquisition}

The following variables were obtained from the data set: patient's age, sex, presence of prehospital hypotension or hypoxemia, location of arrest (in v. out of hospital), primary rhythm of arrest (asystole, pulseless electrical activity or ventricular fibrillation/ventricular tachycardia), presence of witness to arrest, bystander cardiopulmonary resuscitation (CPR), presence of defibrillation, time to return of spontaneous circulation (ROSC), post-arrest Glasgow Coma Score (GCS) and mean arterial pressure, admission Acute Physiology and Chronic Health Evaluation II score, and use of therapeutic hypothermia. Outcome measure was the functional status as measured by the Cerebral Performance Categories (CPC) scale. The CPC has five categories ranging from good cerebral performance (CPC 1) to death (CPC 5).

\section{ONSD measurement}

Images were obtained with a General Electric CT scanner in a standardized protocol producing contiguous non-contrast 2-mm slices from the base of the skull to the vertex. Images were viewed on Inteliviewer (Intelerad Medical Systems, Montreal QC) in the "abdomen" window (Hounsfield range +25 to +40 ) at magnification level $3 \times$, which demonstrated the optic 
nerve sheaths in greatest detail. Following training by a neurointensivist (MS), three investigators (BR, $\mathrm{AW}$, LB) measured the right and left ONSD $3 \mathrm{~mm}$ behind the optic papilla and perpendicular to the linear axis of the optic nerve. Right- and left-sided values were averaged for final analysis. All investigators were blinded to the CPC score and outcomes of the patients during ONSD measurement.

\section{Statistical analysis}

Data were analysed using SAS v9.3 (Cary, NC, USA). Normally distributed data were analysed using the t-test; for non-normally distributed data, the Wilcoxon Rank Sum test was used. The ONSD was treated as a continuous variable; however, the $\mathrm{CPC}$ score was dichotomized.

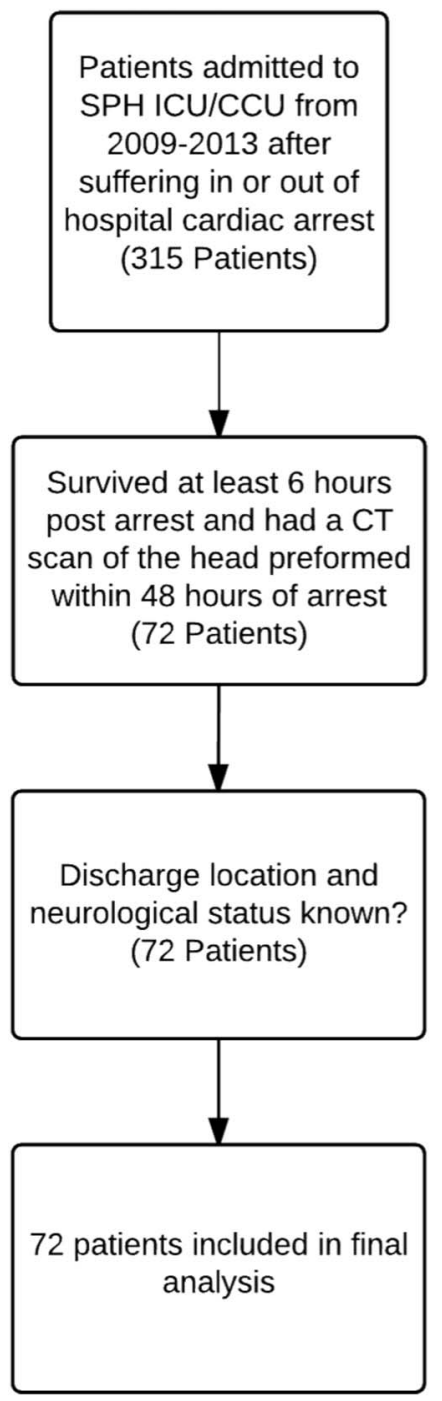

Figure 1. Patient selection diagram.
A score of 2 or less on the CPC scale was considered a good outcome, whereas a score of 3 or more was classified as a poor neurological outcome. Intra-class correlation coefficients (ICC) was calculated between the three groups of ONSD measurers and equaled 0.94 (95\% CI 0.89-0.97).

A logistic regression model was created to model good versus poor neurological outcome. Variables included in the model were age, witness to arrest, time to ROSC, initial GCS, location of arrest, presence of bystander CPR, shockability of rhythm, and ONSD treated as a continuous variable. Two further models were created treating ONSD as a dichotomized variable at $>8 \mathrm{~mm}$ and $>7 \mathrm{~mm}$ in order to ascertain whether a cut-off level for ONSD would help predict neurological outcome. The $\mathrm{C}$ statistic for the main model with ONSD as a continuous variable was 0.95 .

\section{RESULTS}

A total of 72 cardiac arrest survivors who met the inclusion criteria were included in the analysis; $54(75.0 \%)$ of the patients had a poor neurological outcome, whereas $18(25.0 \%)$ patients were discharged from the hospital with a CPC score of $\leq 2$ (Table 1 ).

\begin{tabular}{|c|c|c|c|}
\hline & $\begin{array}{c}\text { Good outcome } \\
\qquad \begin{array}{c}(\mathrm{CPC} \leq 2) \\
n=18\end{array}\end{array}$ & $\begin{array}{l}\text { Bad outcome } \\
\qquad \begin{array}{c}(\mathrm{CPC} \geq 3) \\
n=54\end{array}\end{array}$ & $P$ value \\
\hline Age, mean (SD) & $57.7(15.3)$ & $64.1(15.1)$ & 0.12 \\
\hline Male gender, $n(\%)$ & 15 (83.3) & 45 (83.3) & 0.99 \\
\hline $\begin{array}{l}\text { Time to ROSC } \\
\text { minutes, } n \text { (SD) }\end{array}$ & $9.3(7.8)$ & $27.7(15.0)$ & $<0.0001$ \\
\hline $\begin{array}{l}\text { Witnessed arrest, } \\
n(\%)\end{array}$ & $17(94.4)$ & $41(76.0)$ & 0.09 \\
\hline $\begin{array}{l}\text { Shockable rhythm, } \\
n(\%)\end{array}$ & 7 (38.9) & $15(27.8)$ & 0.79 \\
\hline Bystander CPR, $n(\%)$ & 16 (88.9) & $43(79.6)$ & 0.50 \\
\hline $\begin{array}{l}\text { Out-of-hospital arrest, } \\
n(\%)\end{array}$ & $10(55.6)$ & $38(70.4)$ & 0.26 \\
\hline Defibrillation, $n(\%)$ & 7 (38.9) & $22(40.7)$ & 0.89 \\
\hline GCS, mean (range) & $6(3-15)$ & $4(3-11)$ & 0.02 \\
\hline $\begin{array}{l}\text { Time to CT head in } \\
\text { hours, mean (SD) }\end{array}$ & $9.3(10.0)$ & $10.2(11.2)$ & 0.75 \\
\hline \multicolumn{4}{|l|}{ ONSD (mm) } \\
\hline Right (SD) & $6.62(0.68)$ & $6.57(0.79)$ & 0.80 \\
\hline Left (SD) & $6.70(0.92)$ & $6.63(0.89)$ & 0.76 \\
\hline Average (SD) & $6.66(0.78)$ & $6.60(0.82)$ & 0.77 \\
\hline
\end{tabular}

ROSC = return of spontaneous circulation; GCS = Glasgow Coma Scale; ONSD = optic nerve sheath diameter; $\mathrm{SD}=$ standard deviation. 
Of the poor outcome group, $53(98.1 \%)$ patients died in the hospital. The time to ROSC for patients with a good outcome was 9.3 minutes (SD 7.8), compared to 27.7 minutes (SD 15.0) for patients with a poor outcome $(p<0.0001)$. The mean initial GCS for good outcome patients was 6 (range 3-15), compared to 4 (range 3-11) for patients with a poor outcome $(p=0.02)$. There was a trend towards benefit for witnessed arrest $(94.4 \%$ v. $76.0 \%, p=0.09)$ and age $(57.7$ years SD 15.3 v. 64.1 SD 15.1, $p=0.12$ ) for a good functional outcome; however, these were not statistically significant. There were no observed differences in male gender $(83.3 \%$ v. $83.3 \%, p=0.99)$, shockable rhythm (38.9\% v. $27.8 \%, p=0.79)$, bystander CPR $(88.9 \%$ v. $79.6 \%, p=0.50)$, defibrillation $(38.9 \%$ v. $40.7 \%, p=0.89)$, or out-of-hospital location $(55.6 \% \mathrm{v}$. $70.4 \%, p=0.26$ ) between the two groups.

A CT head was obtained for patients in the good outcome group in a mean time of 9.3 hours (SD 10.0) compared to 10.2 hours (SD 11.2) for the poor outcome group $(p=0.75)$. There was no difference in average ONSD observed between the two outcome groups (6.66 mm SD 0.78 v. $6.60 \mathrm{~mm} \mathrm{SD} \mathrm{0.82,} p=0.77$ ).

Multiple logistic regression failed to show any association between ONSD and neurological outcome when adjusted for all other covariates (OR 1.32 95\% CI $0.40-4.34, p=0.65$, Table 2). Setting an ONSD threshold of $>8 \mathrm{~mm}$ (OR 2.32 95\% CI 0.14-39.40, $p=0.55)$ or $>7 \mathrm{~mm}$ (OR $0.28,95 \%$ CI $0.03-2.77$,

\begin{tabular}{|c|c|c|c|c|}
\hline & Coefficient & OR & $95 \% \mathrm{Cl}$ & $P$ value \\
\hline \multicolumn{5}{|l|}{ Model 1} \\
\hline Age in years & 0.1431 & 1.15 & $1.03-1.29$ & 0.01 \\
\hline $\begin{array}{l}\text { Time to ROSC } \\
\text { minutes }\end{array}$ & 0.3599 & 1.43 & $1.12-1.83$ & 0.01 \\
\hline Witnessed arrest & -1.5484 & 0.21 & $0.01-4.80$ & 0.33 \\
\hline GCS & -0.1266 & 0.88 & $0.64-1.21$ & 0.43 \\
\hline $\begin{array}{l}\text { Shockable } \\
\text { rhythm }\end{array}$ & -0.2765 & 0.76 & $0.09-6.58$ & 0.80 \\
\hline Bystander CPR & -2.3333 & 0.10 & $0.01-3.41$ & 0.20 \\
\hline $\begin{array}{l}\text { Out-of-hospital } \\
\text { arrest }\end{array}$ & 3.2590 & 26.02 & $1.04-654.01$ & 0.04 \\
\hline ONSD in mm & 0.2750 & 1.32 & $0.40-4.34$ & 0.65 \\
\hline \multicolumn{5}{|l|}{ Model 2} \\
\hline ONSD > $8 \mathrm{~mm}$ & 0.8451 & 2.32 & $0.14-39.40$ & 0.55 \\
\hline \multicolumn{5}{|l|}{ Model 3} \\
\hline ONSD > $7 \mathrm{~mm}$ & -1.2628 & 0.28 & $0.03-2.77$ & 0.28 \\
\hline
\end{tabular}

$p=0.28)$ also failed to show any association on neurological outcome. Age in years (OR 1.15, 95\% CI $1.03-1.29, p=0.01$ ), Time to ROSC (OR 1.43, 95\% CI $1.12-1.83, p=0.01)$ and out-of-hospital arrest (OR 26.02, 95\% CI 1.04-654.01, $p=0.04$ ) were predictive of a poor neurological outcome.

\section{DISCUSSION}

We found that the ONSD as measured on CT scan was not an independent predictor of poor neurological outcome in a cardiac arrest population. This was observed on both univariate as well as multiple logistic regression analysis. The ONSD did not differ significantly between the two groups. These results are in disagreement with the findings published by Kim et al. ${ }^{12}$

The importance of relying on an imaging parameter to determine prognosis justifies studies of replication. Thus, we aimed to replicate the work of Kim et al., in order to assess the validity of the ONSD in a similar population. $^{12}$ We studied a more homogeneous population of cardiac arrest patients, because patients suffering drowning, poisoning, and other non-cardiac arrests were included in their analysis. The mean value for ONSD was larger than that of Kim et al., but was less than previously reported in the TBI population. ${ }^{14}$ This difference may be due to differences in CT scanning techniques, window of measurement, or timing of CT scan. Our CT scans were performed on average 10 hours after arrest, whereas those in the study by Kim et al. were performed on avserage 1 hour after ROSC.

As the understanding and management of patients who suffer HIBI post-cardiac arrest evolve, more information as to the pathology of brain injury in HIBI patients will hopefully become available. Intracranial hypertension has been shown to occur late in post-arrest patients, potentially due to hyperemic perfusion. ${ }^{15}$ The cause for cardiac arrest may also contribute to the degree of cerebral edema and HIBI. Arrests caused by respiratory failure cause cerebral hypoxia before the cessation of cardiac function, potentially worsening the degree of brain injury compared to ischemic arrests. ${ }^{16}$

The measurement of ONSD on CT scan, as with any measurement, contains a certain degree of uncertainty and error. We attempted to minimize measurement error by having three trained blinded investigators measure the ONSD separately. As demonstrated by the ICC of 0.94 , there were no significant differences between the measurements obtained by the three 
investigators. For ONSD to be a clinically useful tool, it must be able to be measured by clinicians accurately with minimal training.

Our study must be interpreted within the context of the study design. Because it was a single-centre retrospective analysis, the conclusions must be interpreted with caution. Variations in CT scan technology, interpretation of ONSD as well as the clinical care of patients who suffer cardiac arrest may differ between practice locations. The cohort of patients studied also suffered cardiac arrest from a variety of causes, including hypoxemic arrests. It is possible that the natural history of HIBI post-arrest varies, depending on the cause of arrest.

The neurological prognostication of patients with cardiac arrest continues to be a difficult clinical decision. Clinicians must rely on multiple sources of data, including physical exam, laboratory values, as well as imaging in order to make the best decision for their patients. For prognostic markers to be useful, they must be unambiguous, reliable, reproducible, and precise. Our findings should bring a degree of caution into the utilization of ONSD for prognostic decision-making, post-cardiac arrest. Further large prospective multi-centre studies would help delineate the true role of ONSD in providing prognostic information for these patients.

Financial support: The VGH \& UBC Hospital Foundation Best of Health Fund supported this research.

Competing interests: None declared.

\section{REFERENCES}

1. Wijdicks EFM, Hijdra A, Young GB, et al. Quality Standards Subcommittee of the American Academy of Neurology. Practice parameter: prediction of outcome in comatose survivors after cardiopulmonary resuscitation (an evidence-based review): report of the Quality Standards Subcommittee of the American Academy of Neurology. Neurology 2006;67(2):203-10.

2. Topcuoglu MA, Oguz KK, Buyukserbetci G, et al. Prognostic value of magnetic resonance imaging in postresuscitation encephalopathy. Intern Med Tokyo Zpn 2009; 48(18):1635-45.

3. Naples R, Ellison E, Brady WJ. Cranial computed tomography in the resuscitated patient with cardiac arrest. $A m \mathcal{Z}$ Emerg Med 2009;27(1):63-7.
4. Finelli PF, DiMario FJ. MR imaging and prognosis of hypoxic-ischemic leukoencephalopathy. Neurocrit Care 2006;4(2):119-26.

5. Samaniego EA, Mlynash M, Caulfield AF, et al. Sedation confounds outcome prediction in cardiac arrest survivors treated with hypothermia. Neurocrit Care 2011; 15(1):113-9.

6. Fugate JE, Wijdicks EFM, Mandrekar J, et al. Predictors of neurologic outcome in hypothermia after cardiac arrest. Ann Neurol 2010;68(6):907-14.

7. Launey Y, Nesseler N, Le Maguet P, et al. Effect of osmotherapy on optic nerve sheath diameter in patients with increased intracranial pressure. 7 Neurotrauma 2014; 31(10):984-8.

8. Helmke K, Hansen HC. Fundamentals of transorbital sonographic: evaluation of optic nerve sheath expansion under intracranial hypertension. II. Patient study. Pediatr Radiol 1996;26(10):706-10.

9. Sekhon MS, Griesdale DE, Robba C, et al. Optic nerve sheath diameter on computed tomography is correlated with simultaneously measured intracranial pressure in patients with severe traumatic brain injury. Intensive Care Med 2014;40(9):1267-74.

10. Sekhon MS, McBeth P, Zou J, et al. Association between optic nerve sheath diameter and mortality in patients with severe traumatic brain injury. Neurocrit Care 2014; 21(2):245-52.

11. Brain Trauma Foundation, American Association of Neurological Surgeons, Congress of Neurological Surgeons. Guidelines for the management of severe traumatic brain injury. 7 Neurotrauma 2007;24(Suppl 1): S1-106.

12. Hwan Kim Y, Ho Lee J, Kun Hong C, et al. Feasibility of optic nerve sheath diameter measured on initial brain computed tomography as an early neurologic outcome predictor after cardiac arrest. Acad Emerg Med Off 7 Soc Acad Emerg Med 2014;21(10):1121-8.

13. Vandenbroucke JP, von Elm E, Altman DG, et al. Strengthening the Reporting of Observational Studies in Epidemiology (STROBE): explanation and elaboration. Epidemiol Camb Mass 2007;18(6):805-35.

14. Legrand A, Jeanjean P, Delanghe F, et al. Estimation of optic nerve sheath diameter on an initial brain computed tomography scan can contribute prognostic information in traumatic brain injury patients. Crit Care Lond Engl 2013; 17(2):R61.

15. Iida K, Satoh H, Arita K, et al. Delayed hyperemia causing intracranial hypertension after cardiopulmonary resuscitation. Crit Care Med 1997;25(6):971-6.

16. Morimoto Y, Kemmotsu O, Kitami K, et al. Acute brain swelling after out-of-hospital cardiac arrest: pathogenesis and outcome. Crit Care Med 1993;21(1):104-10. 